\author{
꽃게 통발용 미끼의 유인효과 \\ 장호영* · 구재근' · 이근우 \\ 군산대학교 해양생산학전공, ${ }^{1}$ 군산대학교 식품생명공학전공
}

\title{
Attracting effect of baits used in trap for swimming crab*
}

\author{
Ho Young Chang*, Jae Geun Koo ${ }^{1}$, Keun Woo LeE ${ }^{1}$ and Bong Kon ChO \\ Marine Science \& Production Program, Kunsan National University, Jeonbuk 573-701, Korea \\ ${ }^{1}$ Food Science \& Biotechnology Program, Kunsan National University, Jeonbuk, 573-701, Korea
}

In order to develop the artificial bait of trap for swimming crabs, the attracting effect was analyzed in the duration time of attracting effect, preference and shape recognition to the bait in the water tank and field experiments. According to the result which investigated the mean entrapped number of swimming crabs into the trap for each bait(mackerel, sardine and anchovy) in water tank experiments, the mean entrapped number was found to be higher in the trap with mackerel(6.9 ind.; $23.0 \%)$ than in other traps with sardine(5.2 ind.; $17.3 \%$ ) and anchovy(3.4 ind.; $11.3 \%$ ). In addition, the mean entrapped ratios of swimming crabs into the traps for 3 kinds of baits were estimated to be over $80 \%$ all in 5 hours after soaked in the water tank. For preference of swimming crabs to 3 kinds of baits, the trap with mackerel(6.9 ind.; $23.0 \%)$ was evaluated to be higher than the traps with sardine(2.8 ind.; 9.3\%) and anchovy(0.2 ind.; $0.7 \%)$. In the field experiments, the mean entrapped number of swimming crabs into the trap with mackerel and sardine were found to be similar as 120 and 118 ind., but the trap with anchovy was only 85 ind.. According to the result which investigated the shape regnition of swimming crabs to the bait used mackerel, divided into 8 pieces, 16 pieces and grinded mass in water tank experiments, the mean entrapped number of swimming crabs into the traps that includes the mackerel divided into several pieces was significantly decreased. Moreover, by the presence of skin of mackerel for bait, there was a great difference in the entrapped number of swimming crabs. Therefore, it was thought that the swimming crab was attracted to the bait and entrapped into the trap would indicate that not only the chemical stimuli such as the attactant, but also the visual stimuli such as the shape recognition to the bait might be closely related.

Key words : Attracting effect, Bait, Trap, Swimming crab

\footnotetext{
*Corresponding author: hyjang@kunsan.ac.kr, Tel: 82-63-469-1819, Fax: 82-63-469-1811
} 


\section{서 론}

통발 어구는 어법 특성상 어구 - 어법 및 조업 의 간편함, 능률적인 어구인 점, 심해의 수산생 물에 적용할 수 있는 점, 저층 끌어구 - 저층 연 승 등과 같은 조업이 불가능한 해저에서도 사용 할 수 있다는 점 등의 장점을 갖고 있으며, 다른 업종에 비해 비교적 수익률이 높은 업종으로서 연근해어업에서 중요한 위치를 차지하고 있다 (Inoue, 1985). 통발 어구의 어획효율은 통발의 구조나 어장학적 요소 및 사용하는 미끼에 따라 크게 좌우되는데, 그 중에서도 미끼의 요인은 통 발 어업의 성립과 밀접한 관련을 갖고 있다.

한편, 통발 어업에서 미끼 구입비가 차지하는 비중은 전체 어업경비 중 $8-10 \%$ (출어경비의 $30-40 \%$ ) 정도를 차지하고 있으며(Chang, 2003), 꽃게 통발용 미끼로 주로 사용되고 있는 고등어의 어획은 한 - 일, 한 - 중 어업협정 등으 로 인하여 연근해어장이 대폭 축소됨으로서 1988년 약 17만M/T에서 2003년 약 12만M/T으 로 어획량이 격감하고 있는 실정이다. 또한, 꽃 게 통발어업에서 사용되는 미끼는 주로 냉동 고 등어를 해동시켜 3-6토막으로 절단하여 사용 하고 있으므로, 조업 중 미끼를 손질하는 데 노 동력이 필요하여 조업효율이 떨어지고, 특히 기 온이 상승하는 하계에는 냉동 고등어가 변질되 기 쉬우므로 보관 및 취급상 문제가 있다. 따라 서, 가격이 저렴하고, 취급이 간편하며, 변질의 우려가 적고, 유인효과가 우수한 인공미끼의 개 발이 절실히 요구되고 있다.

유인물질에 관한 연구로서는 $\operatorname{Hara(1982),~}$ Takeda et al.(1984), Harada(1986), Johnstone et al.(1990), Takaoka et al.(1990) 등이 어류나 수서동 물에 대한 유인물질로서 수용성 저분자물질인 아미노산, 이노신, IMP, ADP, DMPT, 글리신, 베 타인 등의 역할을 규명한 바 있으며, 갑각류에 대 한 유인물질에 대하여서는 Carr and Thompson (1983), Carr and Derby(1986), Zimmer-Faust (1989) 등의 연구가 있었으나, 기초적인 연구단계에 불
과하였다. 뿌림용 미끼나 연승용 미끼 등의 개량 을 위한 연구가 Umezu(1966), Hara(1982) 등에 의해 시도되었으며, Miyazaki et al.(1967)의 게 통발용 인공미끼의 개발에 관한 시도가 있었으 나 뚜렷한 연구성과를 나타낸 것은 없었다. 국내 에서는 Kim and Lee(1977)의 멸치와 명태 폐기 물을 미끼로 한 통발의 어획실험이 있었고, 천연 미끼에 대한 붕장어의 반응을 조사한 연구로는 Ko and Kim(1984), Kim(1985), Ko and Kwon (1987), Kim and Lee(1990) 등이 있었으며, Youm (1998) 및 Youm et al.(1990a, b)의 붕장어 인공미 끼에 관한 연구에서 멸치 - 고등어 - 정어리 등 을 마쇄한 붕장어용 건조 펠렛형 제조미끼에서 천연미끼와 유사한 수준의 게류의 어획을 확인 한 바 있으나 실용화에는 이르지 못하였으며, 최 근에는 An et al.(2006)의 문어 흘림낚시용 미끼 개량에 관한 연구가 있었으나, 꽃게 통발용 인공 미끼의 개발에 관한 연구는 거의 없는 실정이다.

따라서, 본 연구에서는 꽃게 통발 조업현장에 서 사용되고 있는 천연미끼를 사용하여 수조실 험 및 현장조사를 통하여 미끼의 유인 지속시간, 미끼의 선호도 및 형태 인식 등에 관한 유인효과 를 분석 - 검토하여 꽃게 통발용 인공미끼의 개 발을 위한 기초 자료로 활용하고자 하였다.

\section{재료 및 방법}

수조실험은 2004년 8월 10-23일, 9월 4-11 일 및 2005년 6월 8-14일까지 충남 보령시 소재 서해수산연구소 자원조성센터 및 전북 부안군 소재 서해수산연구소 부안시험포에 있는 대형 콘크리트 원형수조 $(\phi 64,000 \times 10,600 \mathrm{Hmm})$ 를 이 용하여 각각 미끼의 유인 지속시간, 미끼의 선호 도 및 형태 인식 등에 관하여 조사하였다.

미끼의 유인 지속시간에 대한 조사에서는 3종 류(고등어, 정어리, 멸치)의 미끼를 통발 1 개에 1 종류씩 넣어 3 종류에 대하여 침지시간 9시간 동 안의 매시간별 누적 입롱미수를 조사하였다.

미끼의 선호도 조사에서는 고등어( $\mathrm{M})$, 정어리 

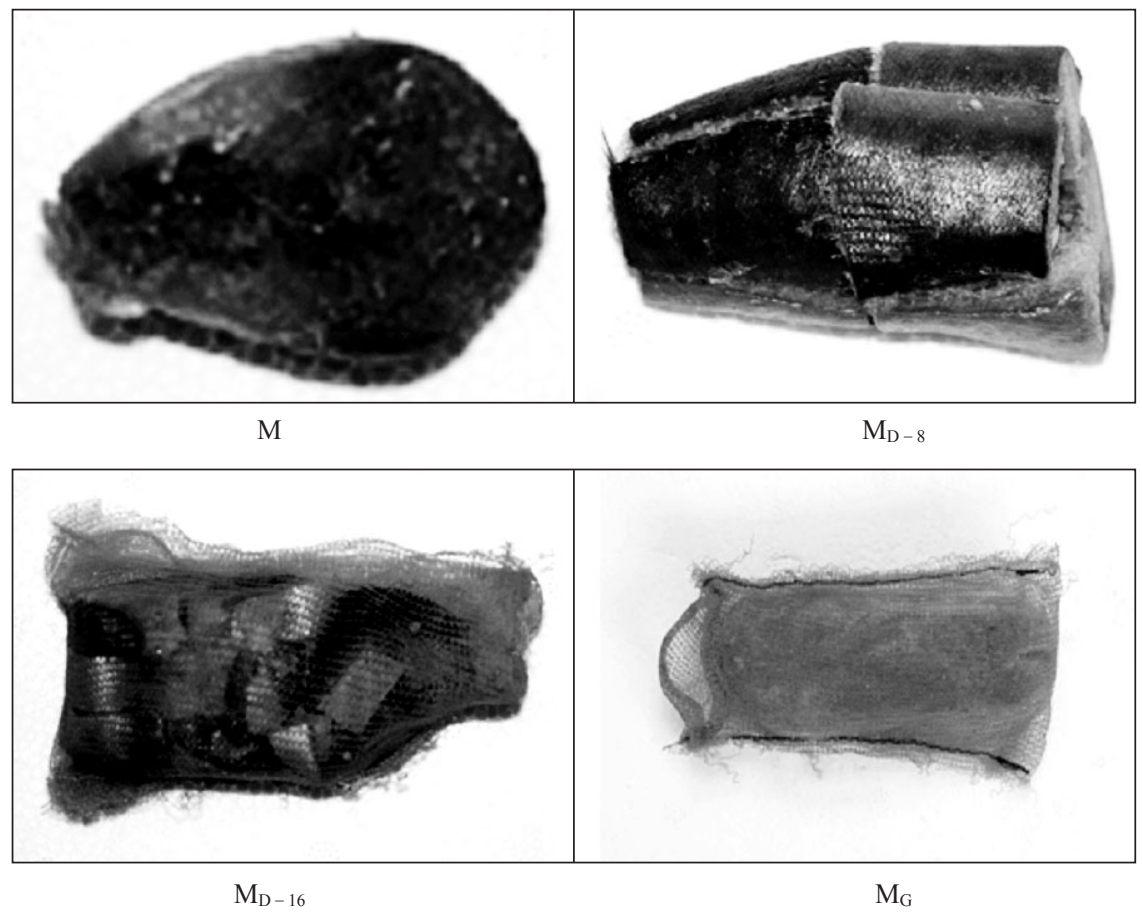

Fig. 1. Baits used to recognize the shape in experiments I .

M: mackerel, $\mathrm{M}_{\mathrm{D}-8}$ : mackerel divided into 8 pieces, $\mathrm{M}_{\mathrm{D}-16}$ : mackerel divided into 16 pieces, $\mathrm{M}_{\mathrm{G}}$ : grinded mackerel.

(S), 멸치(A) 미끼를 각각 넣은 3 개의 통발을 조 중앙 부분에 간격이 약 $3 \mathrm{~m}$ 되게 삼각형으로 배 치하고, 해당 미끼가 투입되는 통발의 위치를 매 회 교체하여 침지시간 9 시간 동안의 입롱미수를 조사하였다.

미끼의 형태 인식에 대한 조사에서는 Fig. 1 과 같은 고등어 $(\mathrm{M}), 8$ 등분 고등어 $\left(\mathrm{M}_{\mathrm{D}-8}\right), 16$ 등분 고 등어 $\left(\mathrm{M}_{\mathrm{D}-16}\right)$, 마쇄한 고등어 $\left(\mathrm{M}_{\mathrm{G}}\right)$ 의 미끼에 대하 여 $\mathrm{M} / \mathrm{M}_{\mathrm{D}-8}, \mathrm{M} / \mathrm{M}_{\mathrm{D}-16}$ 및 $\mathrm{M} / \mathrm{M}_{\mathrm{G}}$ 의 3가지 조합에 대한 유인효과의 비교와 Fig. 2와 같은 고등어 (M)와 표피를 제거한 고등어 $\left(\mathrm{M}_{\mathrm{R}}\right)$ 에 대한 유인 효과를 비교하기 위하여 통발마다 종류별로 미 끼를 각각 넣고 침지시간 6시간 동안의 입롱미 수를 조사하였다.

매 실험마다 사용된 미끼의 중량은 $60 \mathrm{~g}$ 이었으 며, 30마리의 꽃게를 투입하여 10회씩 반복 실험
을 하였다.

꽃게의 입롱행동은 Fig. 3 과 같은 수중 모니터 링 시스템(Video Ray, Canada)을 이용하여 녹화 와 동시에 관찰하면서 입롱미수를 조사하였다. 실험시 수온은 $21.1-25.4^{\circ} \mathrm{C}$ 였으며, 실험에 사용 된 꽃게는 갑장 $64-103 \mathrm{~mm}$, 최대 갑폭 $128-$ $203 \mathrm{~mm}$, 체중 $128-446 \mathrm{~g}$ 이었다.

또한, 시험조업은 2005년 9월 26-30일까지 전북 군산시 선적의 꽃게 통발어선 제 99 명덕호 $(13.00 \mathrm{G} / \mathrm{T})$ 을 용선하여 고등어, 정어리, 멸치의 3 종류에 대한 어획상태를 3회에 걸쳐 조사하였 다. 어구의 침지시간은 각각 1 일로 하였고, 조업 장소는 전북 군산시 말도 부근의 수심 $10-20 \mathrm{~m}$ 인 해역이었다. 시험조업에 사용된 어구는 $\phi 590$ $\times 250 \mathrm{Hmm}$ 망목 $35 \mathrm{~mm}$ 의 통발 210 개를 1 개조로 구성하여 2개조를 사용하였다. 


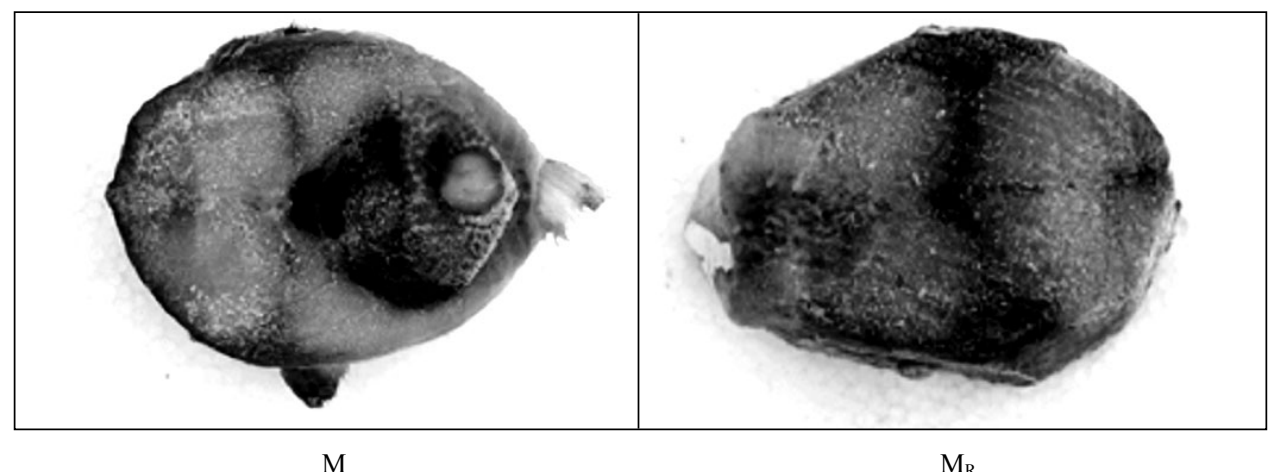

Fig. 2. Baits used to recognize the shape in experiments II . $\mathrm{M}$ : mackerel, $\mathrm{M}_{\mathrm{R}}$ : mackerel removed skin.

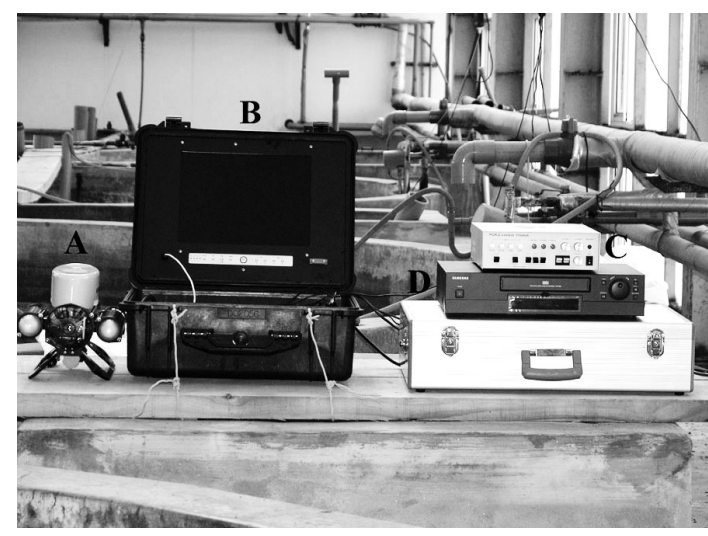

Fig. 3. Underwater monitoring system.

A: underwater video camera,

B: monitor, $\mathrm{C}$ : timer, D: video recorder.

\section{결과 및 고찰}

미끼의 유인효과 지속시간 조사

미끼 종류별 침지시간에 따른 입롱미수는

Table 1 및 Fig. 4와 같다.

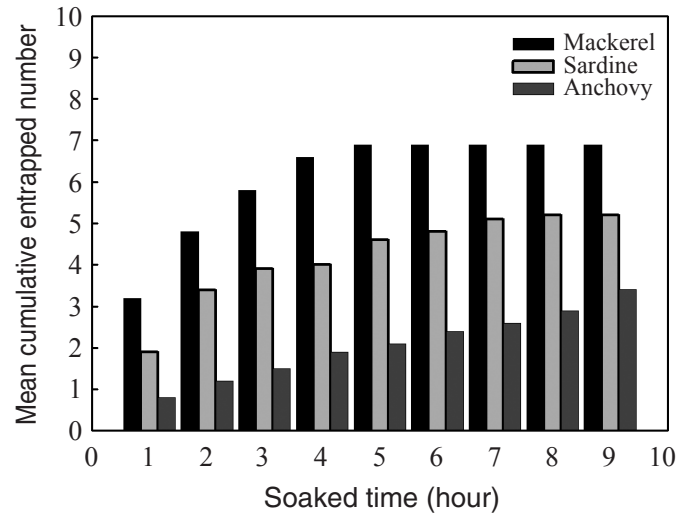

Fig. 4. Frequency distribution of mean cumulative entrapped numbers into the trap for swimming crab by soaked time.

입롱미수는 미끼가 고등어인 경우 평균 6.9 마 리(23.0\%), 정어리인 경우 평균 5.2마리(17.3\%), 멸치인 경우 평균 3.4 마리(11.3\%)로서 고등어를 미끼로 사용하였을 때의 입롱율이 가장 높았다.

Table 1. Mean cumulative entrapped number and rate into the trap by soaked time

\begin{tabular}{|c|c|c|c|c|c|c|c|c|c|c|}
\hline \multirow{2}{*}{$\begin{array}{l}\text { Kind } \\
\text { of baits }\end{array}$} & \multicolumn{9}{|c|}{ Soaked time (hours) } & \multirow{2}{*}{ Total } \\
\hline & 1 & 2 & 3 & 4 & 5 & 6 & 7 & 8 & 9 & \\
\hline Mackerel & $\begin{array}{c}3.2 \\
(10.7)\end{array}$ & $\begin{array}{c}4.8 \\
(16.0)\end{array}$ & $\begin{array}{c}5.8 \\
(19.3) \\
\end{array}$ & $\begin{array}{c}6.6 \\
(22.0) \\
\end{array}$ & $\begin{array}{c}6.9 \\
(23.0) \\
\end{array}$ & $\begin{array}{c}6.9 \\
(23.0) \\
\end{array}$ & $\begin{array}{c}6.9 \\
(23.0) \\
\end{array}$ & $\begin{array}{c}6.9 \\
(23.0) \\
\end{array}$ & $\begin{array}{c}6.9 \\
(23.0) \\
\end{array}$ & $\begin{array}{c}6.9 \\
(23.0) \\
\end{array}$ \\
\hline Sardine & $\begin{array}{c}1.9 \\
(6.3) \\
\end{array}$ & $\begin{array}{c}3.4 \\
(11.3)\end{array}$ & $\begin{array}{c}3.9 \\
(13.0) \\
\end{array}$ & $\begin{array}{c}4.0 \\
(13.3) \\
\end{array}$ & $\begin{array}{c}4.6 \\
(15.3) \\
\end{array}$ & $\begin{array}{c}4.8 \\
(16.0) \\
\end{array}$ & $\begin{array}{c}5.1 \\
(17.0) \\
\end{array}$ & $\begin{array}{c}5.2 \\
(17.3) \\
\end{array}$ & $\begin{array}{c}5.2 \\
(17.3) \\
\end{array}$ & $\begin{array}{c}5.2 \\
(17.3)\end{array}$ \\
\hline Anchovy & $\begin{array}{c}0.8 \\
(2.7)\end{array}$ & $\begin{array}{c}1.2 \\
(4.0)\end{array}$ & $\begin{array}{c}1.5 \\
(5.0)\end{array}$ & $\begin{array}{c}1.9 \\
(6.3)\end{array}$ & $\begin{array}{c}2.1 \\
(7.0)\end{array}$ & $\begin{array}{c}2.4 \\
(8.0)\end{array}$ & $\begin{array}{c}2.6 \\
(8.7)\end{array}$ & $\begin{array}{c}2.9 \\
(9.7)\end{array}$ & $\begin{array}{c}3.4 \\
(11.3)\end{array}$ & $\begin{array}{c}3.4 \\
(11.3)\end{array}$ \\
\hline
\end{tabular}

( ) : mean cumulative entrapped rate into the trap. 
침지시간에 따른 입롱율은 Chang et al.(2003) 의 결과에서와 같이 통발을 침지한 후 대체로 5 시간 정도 경과하면 3종류의 미끼에서 모두 $80 \%$ 이상 입롱하는 것으로 나타났다. 따라서, 꽃게 통발 어업이 행해지는 현장에서의 조류 등 에 의한 영향을 고려하면 미끼에 의한 유인효과 의 지속시간은 더 짧아질 것으로 추정되므로, 침 지시간은 6시간 이내로 하여도 좋을 것으로 생 각된다.

\section{미끼의 선호도 조사}

고등어, 정어리, 멸치의 3 종류에 대한 꽃게의 입롱미수는 Table 2와 같다.

3 종류의 미끼를 넣은 통발에 대한 평균 입롱미 수는 고등어 6.9 마리 $(23.0 \%)$, 정어리 2.8 마리 $(9.3 \%)$, 멸치 0.2 마리 $(0.7 \%)$ 로서 고등어 미끼에 대 한 꽃게의 선호도가 가장 높은 것으로 나타났다.

또한, 2005년 9월 26일부터 9월 30일까지 3회 에 걸쳐 전북 군산시 선적의 꽃게 통발어선 제 99 명덕호(13.00G/T)을 용선하여 전북 군산시 말도 부근의 수심 $10-20 \mathrm{~m}$ 해역에서 고등어, 정어리, 멸치 미끼를 각각 통발 70 개에 넣어 연결한 210 개를 1 개조로 구성하여, 2 개조를 가지고 시험조 업을 실시한 결과는 Table 3 과 같다.

3 회에 걸친 시험조업 결과, 시험어구에 어획

Table 2. Mean cumulative entrapped number and rate into the trap by species of bait

\begin{tabular}{cccc}
\hline Kind of baits & Mackerel & Sardine & Anchovy \\
\hline Entrapped & 6.9 & 2.8 & 0.2 \\
number & $(23.0)$ & $(9.3)$ & $(0.7)$ \\
\hline
\end{tabular}

( ) : mean cumulative entrapped rate into the trap.

Table 3. Results of entrapped number into the trap by species of bait in field experiments

\begin{tabular}{ccccc}
\hline \multirow{2}{*}{$\begin{array}{c}\text { Kind } \\
\text { of baits }\end{array}$} & \multicolumn{3}{c}{ Operation Date } & 27th Sep., \\
\cline { 2 - 4 } & 2005 & 28 th Sep., & 29th Sep., & Mean \\
& 103 & 139 & 119 & 120 \\
\hline Mackerel & 95 & 135 & 126 & 118 \\
Sardine & 95 & 88 & 91 & 85 \\
Anchovy & 76 & 362 & 336 & 323 \\
\hline Total & 274 & & & \\
\hline
\end{tabular}

된 꽃게는 평균 323 마리였으며, 고등어와 정어 리를 미끼로 사용한 통발에서 각각 평균 120 마 리 및 118 마리로 비슷한 수준을 나타내었으나, 멸치를 미끼로 사용한 통발에서는 평균 85 마리 로서 고등어 미끼에 비해 약 $70 \%$ 수준에 불과하 였다.

따라서, 수조실험 및 시험조업 결과에 의하면, 고등어 미끼의 유인효과가 정어리 미끼와 비슷 하거나 다소 우수하며, 멸치 미끼보다는 상당히 우수한 것으로 나타났다. 또한, 미끼의 가격 및 미끼 공급의 편의성 등을 고려할 때, 꽃게 통발 용 인공미끼의 개발을 위한 미끼의 유인효과에 대한 지표(index)로서 고등어를 기준으로 하는 것이 타당한 것으로 확인되었다.

\section{미끼의 형태 인식 조사}

꽃게의 미끼에 대한 형태 인식 여부를 확인하 기 위한 미끼별 입롱미수는 Table 4 및 Table 5와 같다.

Table 4에서와 같이 $\mathrm{M}$ 과 $\mathrm{M}_{\mathrm{D}-8}$ 의 미끼 조합에 서의 입롱미수는 각각 평균 3.2 마리 $(10.7 \%)$ 와 2.2마리(7.3\%), $\mathrm{M}$ 과 $\mathrm{M}_{\mathrm{D}-16}$ 의 미끼 조합에서는 각각 평균 2.1마리(7.0\%)와 1.6마리(5.3\%), $\mathrm{M}$ 과 $\mathrm{M}_{\mathrm{G}}$ 의 미끼 조합에서는 각각 평균 2.3마리(7.7\%) 와 0.3 마리 $(1.0 \%)$ 로서 미끼용 고등어를 많이 조 각낼수록 입롱미수가 급격히 감소하는 것으로 나타났다.

Table 5에서와 같이 미끼용 고등어의 피부를 제거하지 않은 것 $(\mathrm{M})$ 의 입롱미수는 평균 2.4 마 리 $(8.0 \%)$ 인 것에 비해 피부를 제거한 것 $\left(\mathrm{M}_{\mathrm{R}}\right)$ 의

Table 4. Comparison of mean cumulative entrapped number and ratio into the trap by combination of bait

\begin{tabular}{cccc}
\hline $\begin{array}{c}\text { Kind } \\
\text { of baits }\end{array}$ & $\mathrm{M} * / \mathrm{M}_{\mathrm{D}-8} * *$ & $\mathrm{M} / \mathrm{M}_{\mathrm{D}-16} * * *$ & $\mathrm{M} / \mathrm{M}_{\mathrm{G}} * * * *$ \\
\hline $\begin{array}{c}\text { Entrapped } \\
\text { number }\end{array}$ & $\begin{array}{c}3.2 / 2.2 \\
(10.7 / 7.3)\end{array}$ & $\begin{array}{c}2.1 / 1.6 \\
(7.0 / 5.3)\end{array}$ & $\begin{array}{c}2.3 / 0.3 \\
(7.7 / 1.0)\end{array}$ \\
\hline
\end{tabular}

( ) : mean cumulative entrapped ratio into the trap.

*: mackerel, **: divided mackerel into 8 pieces, ***: divided mackerel into 16 pieces, $* * * *$ : grinded mackerel. 
입롱미수는 평균 1.2 마리 $(4.0 \%)$ 로서 피부의 유 무에 따라 입롱율이 크게 차이가 나타났다.

한편, 갯가재(mantis shrimp)는 빛이 겨우 들어 오는 어두운 바다 깊은 곳에서도 체표면에서 나 타나는 형광색에 의하여 동료를 인식하는 등 형 광을 이용하여 서로에게 신호를 보내는 것을 보

Table 5. Comparison of mean cumulative entrapped number and ratio into the trap by existence of skin

\begin{tabular}{ccc}
\hline $\begin{array}{c}\text { Kind } \\
\text { of baits }\end{array}$ & $\begin{array}{c}\text { Mackerel } \\
(\mathrm{M})\end{array}$ & $\begin{array}{c}\text { Mackerel removed skin } \\
(\mathrm{MR})\end{array}$ \\
\hline $\begin{array}{c}\text { Entrapped } \\
\text { number }\end{array}$ & 2.4 & 1.2 \\
& $(8.0)$ & $(4.0)$ \\
\hline
\end{tabular}

( ) : mean cumulative entrapped ratio into the trap.
고한 바 있는데 (Mazel et al., 2003; Wikipedia, 2006), Fig. 5에 나타낸 바와 같이 꽃게(a) 및 중하 (b)의 경우에도 체표면에서 강한 형광을 나타내 는 것이 확인되었다. 따라서, 갯가재와 동일한 시각(視覺) 체계를 갖고 있는 꽃게의 경우에도 빛이 잘 들어오지 않는 깊은 바다에서 형광에 의 해 동료를 인식할 수 있을 것으로 판단된다.

또한, Fig. 6에 나타낸 바와 같이 꽃게 통발용 미끼로 사용되는 고등어의 표면에서도 형광을 나타내는데, 이러한 형광색이 꽃게의 시각목표 가 될 수 있으므로 꽃게 통발용 미끼로 고등어를 사용할 때 조각을 많이 낼수록 미끼 표면의 형상

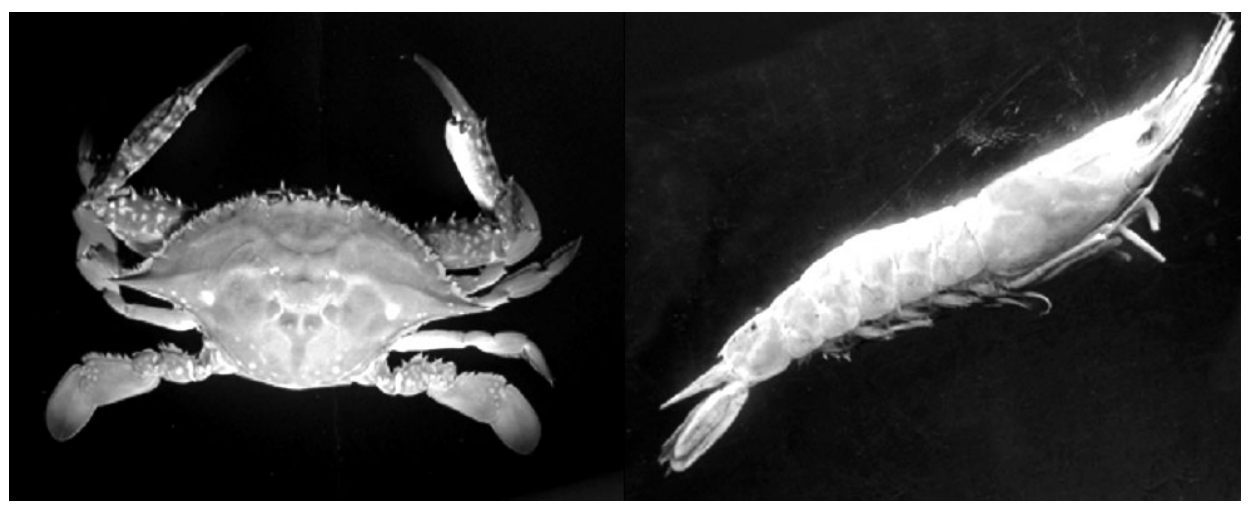

(a)

(b)

Fig. 5. Fluorescent images of swimming crab(a) and medium shrimp(b) under the UV light.

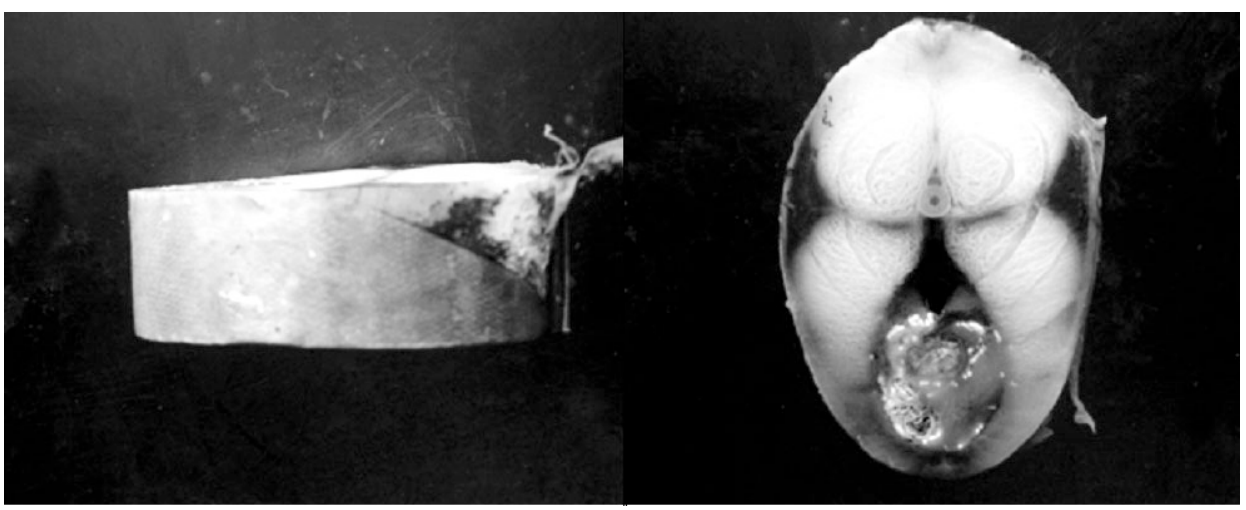

(a) side view

(b) sectional view.

Fig. 6. Fluorescent images of mackerel used in bait of trap for swimming crab under the UV light. 


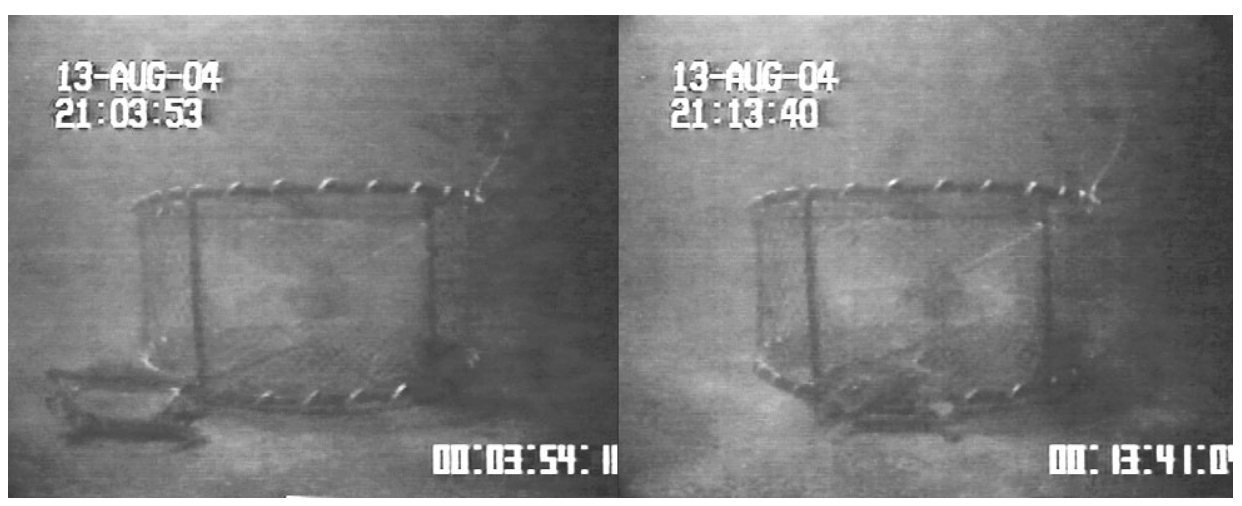

(a)

(b)

Fig. 7. Behavior of swimming crab to bait for trap.

(a) a figure of approaching to the trap, (b) a figure of entrapping into the trap.

은 원형을 잃게 되어 형광을 나타내기 어려워짐 으로서 꽃게가 미끼의 존재를 알아차리기 힘들 게 되어 입롱율이 감소하는 것으로 생각된다.

한편, 수중 모니터링 시스템으로 실시간 관측 및 녹화 비디오 테입을 분석한 결과에 의하면, Fig. 7에서와 같이 꽃게가 미끼가 들어있는 통발 주위로 접근하는 단계에서는 미끼에 의한 유인 물질에 반응하여 후각에 의해 변향 무정위운동 성(klinokinesis)의 행동 패턴을 보이며(Inoue, 1993), 통발 주위 약 $50 \mathrm{~cm}$ 이내로 접근하면 미끼 의 존재를 시각에 의해 확인하여 적극적으로 통 발 속으로 들어가기 위해 입구를 찾는 행동을 보 였다.

따라서, 꽃게가 미끼에 유인되어 통발에 들어 가는 과정은 미끼에 의한 유인물질의 화학적 자 극 뿐만 아니라 미끼의 형태 인식에 의한 시각적 자극도 관계하는 것으로 판단되므로, 꽃게 통발 용 인공미끼의 개발에 있어서는 미끼에 의한 유 인물질의 영향과 함께 시각적 자극을 높일 수 있 는 방안을 강구해야 할 것으로 생각된다.

\section{결 론}

꽃게 통발 조업현장에서 사용되고 있는 천연 미끼를 사용하여 수조실험 및 현장조사를 통하 여 미끼의 유인 지속시간, 미끼의 선호도 및 미
끼의 형태 인식 등에 관한 유인효과를 분석 - 검 토하여 인공미끼의 개발을 위한 기초자료로 활 용하고자 하였다. 미끼 종류별 유인 지속시간을 조사하기 위하여 고등어, 정어리, 멸치 미끼에 대한 각각의 침지시간별 입롱미수를 조사한 결 과, 고등어 미끼인 경우 평균 6.9 마리 $(23.0 \%)$, 정 어리 미끼인 경우 평균 5.2마리(17.3\%), 멸치 미 끼인 경우 평균 3.4 마리(11.3\%)로서 고등어를 미 끼로 사용하였을 때의 입롱율이 가장 높았다. 또 한, 침지시간에 따른 입롱율은 통발을 침지한 후 5 시간 정도 경과하면 3 종류의 미끼에서 모두 $80 \%$ 이상 입롱하는 것으로 나타났다. 미끼의 선 호도를 조사하기 위하여 실험수조에서 고등어, 정어리, 멸치 미끼를 각각 넣은 통발에 대한 입 롱미수를 조사한 결과, 고등어 미끼의 경우 평균 6.9 마리(23.0\%), 정어리 미끼의 경우 2.8 마리 $(9.3 \%)$, 멸치 미끼의 경우 0.2 마리 $(0.7 \%)$ 로서 고 등어 미끼에 대한 꽃게의 선호도가 가장 높은 것 으로 나타났다. 또한, 2005년 9월 26-30일까지 3 회에 걸쳐 시험조업을 실시한 결과, 어획된 꽃 게는 평균 323 마리였으며, 고등어와 정어리를 미끼로 사용한 통발에서는 각각 평균 120 마리 및 118 마리로 비슷한 수준을 나타내었으나, 멸 치를 미끼로 사용한 통발에서는 평균 85 마리로 서 고등어 미끼에 비해 약 $70 \%$ 수준에 불과하였 
다. 따라서, 수조실험 및 시험조업 결과에 의하 면, 고등어 미끼의 유인효과는 정어리 미끼와 비 슷하거나 다소 우수하며, 멸치 미끼보다는 상당 히 우수한 것으로 나타났다. 꽃게의 미끼에 대한 형태 인식 여부를 확인하기 위하여 고등어(M), 8 등분 고등어 $\left(\mathrm{M}_{\mathrm{D}-8)}\right), 16$ 등분 고등어 $\left(\mathrm{M}_{\mathrm{D}-16}\right)$, 마 쇄한 고등어 $\left(\mathrm{M}_{\mathrm{G}}\right)$ 의 미끼를 각각 $\mathrm{M} / \mathrm{M}_{\mathrm{D}-8}$, $\mathrm{M} / \mathrm{M}_{\mathrm{D}-16}$ 및 $\mathrm{M} / \mathrm{M}_{\mathrm{G}}$ 으로 조합한 것의 유인효과 비교와 고등어(M)와 표피를 제거한 고등어 $\left(\mathrm{M}_{\mathrm{R}}\right)$ 의 유인효과를 비교한 결과에 의하면, $\mathrm{M}$ 과 $\mathrm{M}_{\mathrm{D}-}$ 8 의 미끼 조합에서의 입롱미수는 각각 평균 3.2 마리(10.7\%)와 2.2마리(7.3\%), $\mathrm{M}$ 과 $\mathrm{M}_{\mathrm{D}-16}$ 의 미 끼 조합에서는 각각 평균 2.1마리(7.0\%)와 1.6마 리(5.3\%), $\mathrm{M}_{\text {과 }} \mathrm{M}_{\mathrm{G}}$ 의 미끼 조합에서는 각각 평균 2.3 마리(7.7\%)와 0.3 마리(1.0\%)로서 미끼용 고등 어를 많이 조각낼수록 입롱미수가 급격히 감소 하는 것으로 나타났다. 또한, $\mathrm{M}$ 의 입롱미수는 평균 2.4마리 $(8.0 \%)$ 인 것에 비해 $\mathrm{M}_{\mathrm{R}}$ 의 입롱미수 는 평균 1.2 마리(4.0\%)로서 피부의 유무에 따라 입롱율이 크게 차이가 나타났다. 이것은 고등어 를 꽃게 통발용 미끼로 사용할 때 조각을 많이 낼수록 미끼 표면의 형상은 원형을 잃게 되고, 어체 피부에서 나타나는 형광 등에 의한 특별한 시각적 자극이 줄어들게 되어 입롱율이 감소하 는 것으로 생각된다. 따라서, 꽃게가 미끼에 유 인되어 통발에 들어가는 과정은 미끼에 의한 유 인물질의 화학적 자극 뿐만 아니라 미끼의 형태 인식에 의한 시각적 자극도 관계하는 것으로 판 단된다.

\section{사 사}

이 논문은 수산특정연구개발과제 “꽃게 통발 용 인공미끼 개발"(과제번호: 20040032)의 연구 비 지원에 의해 수행되었습니다. 또한, 수조실험 에 많은 도움을 주신 서해수산연구소의 손팔원, 이진호 박사님과 시험조업을 위해 많은 조언과 협조를 아끼지 않으셨는데 지금은 고인이 되신 제99명덕호 정순선 선장님께 감사드립니다.

\section{참고문헌}

An, Y.I., J.Y. Park and J.N. Lee, 2006. Improvement of bait for octopus drift-line in the coastal waters of Gangwon province. Abstracts of the 2006 Joint Meeting of the Korean Societies on Fisheries Science, pp. $29-30$.

Carr, W.E.S. and C.D. Derby, 1986. Chemically stimulated feeding behavior in marine animals. J. Chem. Ecol., 12, 989 - 1011.

Carr, W.E.S. and H.W. Thompson, 1983. Adenosine 5 monophoshpate, an internal regulatory agent, is a potent chemoattractant for a marine shrimp. J. Comp. Phsiol., 153, 47 - 53.

Chang, H.Y., 2003. Analysis on the present business states of coastal and off-shore fisheries by type of fishery. Jour. Fish. Mar. Sci. Edu., 15(2), 166 - 175.

Chang, H.Y., B.K. Cho, K.S. Ko and M.S. Han, 2003. Study on the improvement of gill nets and trap nets fishing for the resource management at the coastal area of Yellow Sea-On the entrapping behavior of fishes into trap nets in the water tank experiment. Bull. Korean Soc. Fish. Tech., 39(1), 56 - 62.

Hara, J.J., 1982. Chemoreception in fishes (ed. by J.J. Hara). Elsevier Sci. Pub. Co., Amsterdam, pp. 433.

Harada, K., 1986. Feeding attraction activities of nucleic acid related compounds for abalone, oriental weather fish and yellowtail. Bull. Japanese Soc. Sci. Fish., 52(11), 1961 - 1968.

Inoue, M., 1985. Fishing gear and fish's behavior. Kouseishakouseigaku, Tokyo, pp. 157.

Inoue, M., 1993. Fish's behavior and fishing method. Kouseishakouseigaku, Tokyo, pp. 105.

Johnstone, A.D.F. and A.M. Mackie, 1990. Laboratory investigations of bait acceptance by the cod, Gadus morthua L.: investigations of feeding stimulants. Fish. Res., 9, $219-230$.

Kim, D.A., 1985. Fishing mechanism of eel and crab pots and their modification. Ph.D. Thesis, National Fisheries College of Pusan, Korea, pp. 1 - 41.

Kim, G.H. and J.H. Lee, 1977. On the improvement of bait for sea eel. Bull. Tongyoung Fisheries Jr. 
College. 12, $17-19$.

Kim, H.S and B.G. Lee, 1990. Response of sea eel to the extracts of mackerel, shad and krill. Bull. Korean Soc. Fish. Tech., 26(2), $125-132$.

Ko, K.S. and B.G. Kwon, 1987. Improvement of sea eel pots. Bull. Korean Fish. Soc., 20(2), 95 - 105.

Ko, K.S. and D.A. Kim, 1984. The behaviour of fishes to the traps and their catch ability. Bull. Korean Fish. Soc., 17(1), $15-23$

Mazel, C.H., T.W. Cronin, R.L. Caldwell and N.J. Marshall, 2003. Fluorescent enhancement of signaling in a mantis shrimp, Science Express (online). 2003.11.13: ENS. 2003.11.14.

Miyazaki, C., S. Yazima, T. Koyama and S. Mitsugi, 1967. Fishing efficiency of feed stuff containing chemical stimulant. Bull. Tokai Reg. Fish. Res. Lab., No. 49, 99 - 103.

Takaoka. O., K. Takii, M. Nakamura, H. Kumai and M. Takeda, 1990. Identification of feeding stimulants for marbled rockfish. Bull. Japanese. Soc. Sci. Fish., $56(2), 345-351$.

Takeda, M., K. Takii and K. Matsui, 1984. Identification of feeding stimulants for juvenile eel. Bull. Japanese. Soc. Sci. Fish., 50, 645 - 651.

Umezu, T., 1966. Behavioral response of fishes to chemical stimuli. Bull. Japanese Soc. Sci. Fish., 32(3), $352-376$.

Wikipedia(The Free Encyclopedia), 2006. http://en. wikipedia.org/wiki/Mantis_shrimp.

Youm, M.G., 1998. The improved artificial trap baits. Bull. Korean Soc. Fish. Tech., 34(2), 185 - 190.

Youm, M.G., S.J. Kang, Y.J. Choi, B.D. Choi and C.W. Cho, 1990a. Studies on the applying attractants - I , Identification of natural baits for sea eels, Astroconger myriaster, in their natural habitats. Bull. Korean Soc. Fish. Tech., 26(4), 317 - 325.

Youm, M.G., Y.J. Choi, S.J. Kang, B.D. Choi and C.W. Cho, 1990b. Studies on the applying attractants - II . Identification of chemical attractants for sea eels, Astroconger myriaster, in their natural habitats. Bull. Korean Soc. Fish. Tech., 26(4), 326 - 332.

Zimmer-Faust, R.K., 1989. The relationship between chemoreception and foraging behavior in crustaceans. Limnol. Oceanogr., 34(7), 1367 - 1374.

2007년 10월 1일 접수

2007년 11월 12일 수리 